\title{
Toddlers' Self-Regulated Compliance to Mothers, Caregivers, and Fathers: Implications for Theories of Socialization
}

\author{
Ruth Feldman and Pnina S. Klein \\ Bar-Ilan University
}

\begin{abstract}
To compare children's socialized behavior to parents and nonparental agents, this study examined self-regulated compliance to mothers and caregivers - an early form of internalization-in 90 toddlers, half of whom were also observed with fathers. Adults were observed in play, teaching, and discipline sessions with the child and were interviewed on child-rearing philosophies. Child cognition and emotion regulation were assessed, and naturalistic observations were conducted at child-care locations. Meanlevel and rank-order stability were found in child compliance to the 3 adults. Child emotion regulation and adult warm control in a discipline situation were related to self-regulated compliance to the mother, caregiver, and father. Compliance to parents correlated with parental sensitivity and philosophies, and compliance to the caregiver correlated with child cognition and social involvement when child-care quality was controlled. Maternal sensitivity and warm control discipline predicted compliance to the caregiver but not vice versa. Results are consistent with theoretical positions on the generalization of socialization from the mother to nonmaternal agents.
\end{abstract}

Although theories of socialization have been proposed throughout the 20th century from diverse perspectives, recent years have seen a renewed interest in the perspective linking socialization and moral internalization. This view has underlined the dialogic nature of child socialization, suggesting that children's adherence to rules of conduct and internalization of a moral code emerge from the matrix of their early relationships with their parents (Emde, 1992; Kochanska, 1991, 1994; van IJzendoorn, 1997). Socialization and internalization, according to this perspective, are linked to the child's experiences within close relationships, particularly to the parental handling of intimate encounters, discipline settings, and the negotiation of disputes.

Several researchers describe the development of child compliance as an important milestone in the trajectory leading from the first mother-infant dialogue to the attainment of self-regulation. The original work of Baumrind (1967) specified a parental disciplinary style combining warmth with clear boundaries and minimizing power assertion as central to the promotion of child compliance and later socialization. Kopp (1982) outlined the emergence of self-regulation across the first years, citing both the maturation of inhibitory structures and mutuality in the motherinfant dyad as antecedents of child compliance to parental requests

Ruth Feldman, Department of Psychology, Bar-Ilan University, Ramat Gan, Israel; Pnina S. Klein, Department of Education, Bar-Ilan University, Ramat Gan, Israel.

This study was supported in part by the I. B. Harris Program for Infants, Toddlers, and Families in Israel (ITF) and by the Machado Chair for Research on Human Modifiability, Bar-Ilan University.

We thank Liat Seifan, Liat Cohen-Reuveni, Judy Zaltsman, and Zilly Shochat from the Baker Center at Bar-Ilan University and the parents, children, and caregivers who participated in the study.

Correspondence concerning this article should be addressed to Ruth Feldman, Department of Psychology, Bar-Ilan University, Ramat Gan 52900, Israel. E-mail: feldman@mail.biu.ac.il and pinpointing the child's 2nd birthday as a hallmark in the attainment of self-control. The comprehensive empirical program of Kochanska (1995, 1997; Kochanska \& Aksan, 1995; Kochanska, Coy, \& Murray, 2001) highlighted child compliance within the mother-child context as the first marker of internalization. Kochanska distinguished between two motivational systems underlying child compliance. The first-committed compliancedescribes an internally motivated embrace of the parental rules that marks the emergence of self-regulation; the second-situational compliance-refers to parent-monitored obedience with little indication of internalization. These two systems follow distinct developmental lines, and the self-regulated version defines a stable child orientation that develops into a more mature form of internalization in the preschool years. According to Kochanska and Aksan (1995), "committed compliance is, in fact, a form of early internalization" (p. 250, italics in original). It had been suggested that self-regulated compliance originates in the mother-infant synchrony during the first months of life (Feldman, Greenbaum, \& Yirmiya, 1999). Synchrony affords infants their first experience in the give-and-receive exchange that forms the basis of any social relationship, lays the foundation for the dialogical style, and promotes later socialization (Schaffer \& Crook, 1980). Yet, although internalized compliance is considered central to socialization, few studies addressed the father's contribution to such compliance or examined child compliance toward adults outside the family setting.

The Generalization of Socialization From the Mother to Nonmaternal Social Agents

A central yet under-researched issue in all theories of socialization is its generalization: How do children generalize the commitments learned within the parent-child relationship to relations with nonparental agents of socialization? Throughout their childhood and adolescence, children internalize culturally accepted social values through interactions with a range of nonparental 
figures: caregivers, teachers, older siblings, and mentors with whom they develop close ties. To date, the underlying hypothesis in theories of socialization has been that the parent-child relationship, especially the parent's handling of discipline issues, shapes the child's later functioning within society at large (Hoffman, 1970; Lytton, 1980; Maccoby, 1992). However, inasmuch as child compliance has been studied mainly within the mother-child context, the degree of consistency between children's socialized behavior toward parents and that toward nonparental figures remains largely unknown.

Compared with other aspects of the adult-child relationship, the issue of generalization from parents to other adults holds a special significance in the domain of socialization. Research in the attachment tradition, for instance, assessing concordance in child attachment to mothers, fathers, and caregivers, did not find strong correlations in children's attachment security to the three adults (Fox, Kimmerly, \& Schafer, 1991; Goossens \& van IJzendoorn, 1990; Howes \& Hamilton, 1992). A common explanation for these findings holds that attachment is a descriptor of relationships, not a trait of individuals; thus, attachment constitutes a systemic construct that, by definition, differs from one relationship to the next (Bridges, Connell, \& Belsky, 1988). In the study of socialization, however, such an explanation is invalid. A developmental account of socialization must describe the link between children's internalization of parental rules and their adherence to the rules imposed by nonkin social agents. Otherwise, the role of parents as the first agents of socialization has little meaning. Further, if children's self-regulation and compliance vis-à-vis parents are unrelated to children's self-regulation and compliance vis-à-vis other adults, it is important to scrutinize those differences and describe the alternative avenues of socialization open to children outside the family setting. Such research is especially important in the toddler years, when major developments occur in the child's representational thinking (Piaget, 1952), sense of morality (Kagan, 1984), and social relationships with peers (Howes \& Matheson, 1992). These developments deepen the toddler's awareness of the social world and enable the mental generalization that all social relationships are guided by similar rules of conduct.

\section{Correlates of Child Compliance: Parent and Child Factors}

Compliance, as an early marker of socialization, has been studied in relation to various maternal and child factors, but the role of these factors in shaping child compliance to nonparental agents is still unknown. Child compliance has been repeatedly associated with a parental disciplinary style that is responsive to child cues, places warm and consistent limits, minimizes the use of power, and promotes dialogical strategies such as negotiation, suggestions, and empathy (Crockenberg \& Litman, 1990; Maccoby \& Martin, 1983). Punitive control, on the other hand, has been shown to elicit anger, defiance, and noncompliance (Crockenberg, 1987; Kuczynski, Kochanska, Radke-Yarrow, \& Girinius-Brown, 1987). Thus, two compliance-promoting components are emphasized in the parental style as central to socialization-sensitivity and limit setting-and these components are likely to be associated with internalized compliance to social agents both within and outside the family.
In addition to the maternal handling of direct discipline issues, the mother's general sensitivity in nondisciplinary encounters is related to child compliance (Stayton, Hogan, \& Ainsworth, 1971), and mother-child mutuality during free interactions has been shown to predict self-regulated compliance (Feldman, Greenbaum, \& Yirmiya, 1999; Kochanska \& Murray, 2000). It is thus of interest to determine whether sensitivity on the part of the nonparental agent, observed during relaxed moments, is also associated with children's self-regulated compliance. In the same vein, the adult's strategies while teaching children new skills are likely to be related to child socialization. Compliance and internalization are theorized to emerge on the basis of developments that occur in the 2nd year, especially the toddler's increasing ability to decontextualize concrete information and symbolically represent chains of actions and their consequences (Kagan, 1984; Piaget, 1952). The scaffolding techniques of parents and teachers are central to the regulation of the learning process and the consolidation of symbolic skills, provide tools for the emergence of internalization (Vygotsky, 1978), and may thus be related to self-regulated compliance.

Recent perspectives on socialization have emphasized the role of temperament in the development of compliance and internalization-in particular, emotion regulation and self-control skillsand have pointed to the interaction of child temperament and parenting behavior in shaping socialization (Feldman, Greenbaum, \& Yirmiya, 1999; Kochanska, 1997; Stifter, Spinard, \& BraungartRieker, 1999). Cognitive and linguistic abilities have similarly been associated with child compliance to the mother (Kaler \& Kopp, 1990; Lawrence, 1984). Yet the links between child compliance to nonparental agents and emotion regulation and cognitive skills have not been studied in depth.

Finally, the child-rearing philosophies of parents and other social agents are important determinants in the socialization of children. Parental child-rearing philosophies that respect the child's autonomy, consider the role of social agents in shaping development, and value the relations with other adults in the child's life promote compliance and adaptation (Kochanska, 1991; Kuczynski, 1984). The parent's sense of self-efficacy has also been shown to predict child compliance (Sanders, Turner, Wall, Waugh, \& Tully, 1997), and parental attitudes that advocate a protective, child-sensitive approach (Hastings \& Rubin, 1999) and call for age-related competence (Kuczynski \& Kochanska, 1995) are conducive to socialization. Similarly, van Ijzendoorn, Tavecchio, Stams, Verhoeven, and Reiling (1998) found that close relations between parents and caregivers contribute to children's well-being. Thus, adult philosophies marked by respect, efficacy, and belief in the malleability of development are likely to be related to more optimal socialization outcomes.

\section{Caregiver-Child Relationships and Children's Self-Regulated Compliance}

Although little information is available on children's one-onone relationships with their caregivers, child care and its effects on socialization have become a central topic in developmental research (for a review, see Erel, Oberman, \& Yirmiya, 2000). Specifically, the relations between nonmaternal care and noncompliance have stimulated intense debates. Whereas some researchers have argued that extensive nonmaternal care in infancy places 
children at high risk for noncompliance and aggression (Baydar \& Brooks-Gunn, 1991), others have found no conclusive evidence for such links (NICHD Early Child Care Research Network, 1998). The former perspective is guided by the assumption that since mothers are the first socializing agents, limited chances for mother-infant mutuality may disrupt the socialization process (Belsky, 1990). On the other hand, Howes and Olenick (1986) found that children in high-quality care were more compliant than either children in low-quality care or children not in center care, which points to the role of positive child-care experiences in promoting socialization.

In the present study, however, we aimed to address the relations between child care and child compliance from a different angle. Rather than assessing the relations between the extent and quality of child care and compliance to the mother, we examined internalized compliance to the mother, the caregiver, and the father and the differential relations of such compliance to the adults' behavior and the child's cognition and temperament. These data may point to the specific components in the child's relationships outside the family setting that promote socialization and internalization.

In sum, in the present study we examined toddlers' selfregulated compliance to parents and caregivers-an early form of internalization - to determine if there were consistencies in children's internalized compliance to different social agents. It is important to note, however, that by using a correlational design, longitudinal or contemporaneous, one cannot prove the theory that socialization is generalized from parents to nonparental agents or validate the direction of the effect. It is possible that a third factor, such as temperament, accounts for the stability in socialized behavior, or that once children enter out-of-home care, the routines of center care provide coherence to the child's behavior toward the various social agents. However, inasmuch as current theories of social development build on the assumption that socialization begins at home, the present study may provide a first step toward investigating this issue. Three questions were examined:

1. The stability of self-regulated compliance: Is there stability in children's self-regulated compliance to parents and nonparental agents? Both mean-level and rank-order stability (concordance) were examined. Kagan (1980) and Rutter (1984), addressing the issue of developmental continuities, suggested that when a developmental phenomenon exhibits both mean-level and rank-order stability, the level of consistency over time and situations is considered to be higher. In line with theoretical perspectives, we expected both mean-level and rank-order stability in children's compliance to mothers and caregivers. On the basis of previous research that showed higher compliance to fathers (Lytton, 1979; Power, McGrath, Hughes, \& Manire, 1994), we expected selfregulated compliance to fathers to be higher than that to mothers. Mean-level and rank-order stability were also examined for the adult's and the child's interactive behavior during free-play and teaching sessions in order to assess whether consistency in internalized compliance emerges in the context of a global consistency in adult and child behavior or whether it is unique to interactions that call for socialized conduct. To further explore the stability in self-regulated compliance, we compared the dynamics of compliance episodes, including the latency to the first episode of selfregulated compliance and the mean duration of compliance episodes between the child and each adult.
2. Correlates of self-regulated compliance: What are the correlates of self-regulated compliance to each social agent? The adult's interactive patterns in three adult-child settings were examined as potential correlates of child self-regulated compliance. These included the adult's sensitivity and limit setting during free play, mediation strategies in a teaching session, and warm control discipline tactics in a discipline situation. The child's emotion regulation, cognitive level, and social involvement at play were examined as the child correlates. On the basis of research that points to the links between adult discipline and child socialization, we hypothesized that the adult's warm control discipline would correlate with self-regulated compliance in all interactions. Similarly, in line with theories on the role of temperament in socialization (Kochanska, 1997), we expected relations between emotion regulation and internalized compliance to all three agents. The adult's sensitivity at play, appropriate mediation of the teaching situation, child-rearing philosophies that included a sense of efficacy and a perception of development as open to social influences, and the child's cognitive level were expected to be associated with selfregulated compliance. However, because these factors were mainly studied within the mother-child context, their relation to children's compliance to fathers and caregivers remains a research question.

3. The prediction of child compliance to the nonparental figure from maternal behavior: Can self-regulated compliance to the caregiver be predicted from maternal interactive behavior? On the basis of theories of socialization, we expected that maternal interactive behavior, including the mother's disciplinary style, global sensitivity, and mediation of the learning situation, would predict child socialization to the nonparental agent but that the reverse would not be found. We thus expected that the prediction from maternal interactive behavior to child compliance to the caregiver would be stronger than the prediction from the parallel caregiver's variables to the child's compliance to the mother. Such findings, although not providing final proof of the generalization of socialization hypothesis, are consistent with the theory that socialization begins at home.

\section{Method}

\section{Participants}

Participants were 90 2-year-old toddlers (mean age $=26.4$ months, $S D=3.69$ ) who were observed with their mothers and with their child-care teachers in individual adult-child sessions and with their child-care teachers in a group setting. Approximately half of the participants $(n=42)$ were also observed with their fathers. Families in which fathers did not participate (citing time constraints as the reason) did not differ on demographic, child, or day-care variables from families in which fathers participated. The toddlers ( 52 boys and 38 girls) were recruited from 16 child-care centers in central Israel that were supervised by the government or by national women's organizations. In these day-care centers, children typically remain from 7:30 a.m. to 4:00 p.m. on Sunday through Thursday and from 7:30 a.m. to 1:00 p.m. on Fridays. The adult-to-child ratio is 1 principal caregiver and 1 or 2 assistants per 8 to 14 toddlers. Sixteen principal caregivers, each from a different child-care center, participated in the study, and each was observed with 5 or 6 children.

Families using the services of these national chains of child-care centers, with branches across the country, represent all social classes of the Israeli population. Families in the current study were all considered middle-class (Harlap, Davis, Grower, \& Prywes, 1977): All children came from two- 
parent families, both partners had completed at least a high-school education (with or without a diploma), and in $87 \%$ of the sample both parents were employed. In all families, the mother had been the primary caretaker of the child since birth (as described by both the mother and the father). Because of the Israeli parental leave practice, all mothers (and none of the fathers) were on maternity leave for the first 3 months of the children's lives and returned to part- or full-time employment when the infants were between 3 and 12 months old. Mothers had completed, on average, 13.9 years of education $(S D=2.17) ; 57 \%$ worked as skilled professionals (e.g., teachers, physicians, social workers), $25 \%$ were employed as nonskilled workers (secretaries, teachers' assistants), and the remainder were unemployed or self-employed. Fathers had completed, on average, 14.26 years of education $(S D=2.57)$; $52 \%$ were employed as skilled professionals, $15 \%$ were self-employed, and the remainder were employed as nonskilled or manual workers.

Families had, on average, 2.56 children, and $28 \%$ of the children in the current study were firstborn. On average, children entered center care at 12.83 months of age $(S D=5.43)$. Parents provided the following reasons for placing their children in day care: $36 \%$ cited work reasons, $24 \%$ mentioned the child's need for social relationships, $18 \%$ pinpointed the child's need for a learning/stimulating environment, and 7\% said they had no choice. Parents provided the following reasons for selecting the particular child-care center: $14 \%$ cited the center's proximity to their homes, $30 \%$ considered friends' recommendations, $8 \%$ visited several centers prior to deciding, $15 \%$ had previous children in the same center, $12 \%$ preferred the center's educational approach, and $13 \%$ said they had no choice.

The principal caregivers in the study were all female; were, on average, 40.56 years old $(S D=13.26)$; had completed an average of 12.5 $(S D=1.59)$ years of education; had, on average, $13.0(S D=8.27)$ years of experience in caring for young infants; and were employed in the same center for an average of $4.12(S D=2.39)$ years.

\section{Procedure}

Observations took place during the last 3 months of the school year (May to July). All toddlers had been in the care of the principal caregiver since the previous September, had spent many hours under her supervision, and were quite familiar with her. Within 1 month, toddlers were observed at home in one (with mother) or two separate (with mother and with father) child-parent sessions, at the child-care center in individual caregiver-child interactions, in a naturalistic group observation at the day-care center, and in developmental testing. Mothers, fathers, and caregivers were each interviewed regarding their child-rearing philosophies. Observations at the child-care center were all conducted with the principal caregiver.

Parent-child observations. Toddlers were visited at home and were videotaped with the mother or in separate identical sessions with the mother and the father. Visits included three interactive sessions between the child and each parent: (a) In free play, the parent and child were videotaped in a free-play session for $10 \mathrm{~min}$. Parents were instructed, "Play with your child as you normally do for ten minutes." No toys were provided, and most parents used the child's toys. (b) In structured play (teaching session), the parent and child played with a set of predetermined toys provided by the experimenter for $10 \mathrm{~min}$ (picture book, puzzle, doll and doll's accessories, tea set, and soap bubbles). (c) A toy-pick up task (compliance situation) was used to assess child compliance and the parent's discipline techniques. The parent was given a cart and was asked to have the child pick up the toys provided by the experimenter. The toy pick-up lasted 8 min or until the task was completed.

Caregiver-child observations. Caregivers were videotaped interacting with each child individually in three interactive sessions (free play, teaching session, and compliance situation) that were identical to the parentchild sessions.

Developmental testing. A developmental psychologist tested each child with the Bayley Scales of Infant Development (2nd ed.; Bayley,
1993). Testing took place in a separate room in the day-care center. The mental development index (MDI), which evaluates the child's cognitive skills, was used in this study. Tests were videotaped for later coding.

Naturalistic child-care observations. The caregiver and the entire group of children in her care were videotaped in their natural setting for 1.5 $\mathrm{hr}$ between 9 a.m. and 11 a.m. on a single day. Activities during this time frame included a structured teaching session, indoor play, snack time, and outdoor play.

Interview on child-rearing attitudes and philosophies. The parents (at home) and the caregiver (at the child-care center) were each interviewed and audiotaped in a 45-min interview, which was constructed for the present study and based on the work of Klein and Alony (1993). Questions tapped the adults' knowledge of child development, ability to handle developmental problems, child-rearing goals, expectations for the child's future, issues of authority and discipline, and feelings of efficacy in affecting the child's growth as well as the nature of the relations with and expectations from the caregiver or the parents. Questions were grouped according to several topics. After the open-ended interview, parents completed a 24-item questionnaire (rated on a 5-point scale) that addressed the same topics. Coding was conducted in line with previous research (Feldman, Weller, Leckman, Kvint, \& Eidelman, 1999). Two coders listened to the audiotaped narratives and rated the adult's response for each topic on a 5-point scale. Reliability testing was conducted on 25 interviews, and the intraclass correlation averaged .88 (range $=.84-.93)$. The narrative score was then averaged with the questionnaire score for the same topic. Three topics were considered in the present study, and the correlations between interview and questionnaire scores were $.73, .69$, and .71 for the three topics, respectively ( $p s<.01, n=148$ ). First, perceived efficacy included five items (averaged) regarding the respondent's perceived skill, knowledge, and efficacy in identifying and successfully handling difficulties in child development ( $\alpha=.72$ ). Second, malleability of development concerned the adult's view on the malleability/determinacy of children's development and included eight items that considered how much adults can shape the course and timing of children's cognitive and emotional growth $(\alpha=.69)$. Third, importance of relations with parents/caregiver included four items that considered the importance the adult attributed to the relationship with the caregiver or parents, the frequency of optimal parentcaregiver contact, and the contribution of such contact to children's wellbeing $(\alpha=.79)$

\section{Coding}

Free play: Adult and child interactive behavior. The adult's global relational style during free play was coded with the Coding Interactive Behavior system (CIB; Feldman, 1998), a global coding system for adultchild interactions that includes 42 codes rated on a 5-point scale. The CIB has been validated in several studies and has shown sensitivity to variation in interactive behavior related to parent gender, child age, cultural background, and biological and social-emotional risk conditions (Feldman, 2000; Feldman, Eidelman, Sirota, \& Weller, 2002; Feldman, Greenbaum, Mayes, \& Erlich, 1997; Feldman, Masalha, \& Nadam, 2001; Keren, Feldman, \& Tyano, 2001). Three factors were used in this study. Adult's Sensitivity included the following codes: acknowledgement of child interactive signals, positive affect, warm and clear vocal quality, appropriate range of affect, creativity-resourcefulness, supportive presence, and adaptation to the child's needs and changing communications (alphas: mother $=.92$, caregiver $=.89$, father $=.93$ ). Adult's Limit Setting included limit setting, consistency of style, provision of an adequate framework for play, and adult's persistence (alphas: mother $=.72$, caregiver $=.74$, father $=.71$ ). Child's Social Involvement included the following child's codes: alertness and enthusiasm, vocal output, initiation, competent use of environment, creative-symbolic play, and joint attention (alphas: mother $=.78$, caregiver $=.83$, father $=.81$ ). The Sensitivity and Limit Setting factors were highly correlated (mother, $r=.66, p<.01, n=$ 
.90 ; caregiver, $r=.61, p<.01, n=90$; father, $r=.72, p<.01, n=42$ ) and were averaged into a composite entitled Adult Sensitive Regulation.

Two graduate students trained to use the CIB coding system coded the interactions after viewing the entire 10-min sessions. Coding of the mother-child and caregiver-child interactions was not conducted by the same person, and father-child interactions were coded after the coders had completed the mothers' and caregivers' sessions. Reliability testing was conducted for 25 adult-child interactions: 10 with mothers, 10 with caregivers, and 5 with fathers. Reliability on all codes exceeded $85 \%$. The intraclass correlation averaged .92 (range $=.85-.97$ ).

Teaching session: Adult's mediation of child learning. The adult's mediation of the child's learning process during structured interactions was coded with the Observing Mediational Interaction system (OMI; Klein, 1996), a coding scheme that has been validated in previous research (Klein, Weider, \& Greenspan, 1987). The OMI evaluates the frequencies of five mediation strategies during adult-child interactions. Two strategies were considered in the present study: Regulating Behavior, which consisted of laying the course of action required for optimal performance through verbal or nonverbal behavior (e.g., placing four pieces in front of the child from the pile of puzzle pieces and saying "Let's do this piece and then that piece"), demonstrating a series of activities, and reminding the child of the sequencing of behavior and commenting on wrong turns as they occurred, and Decontextualization, which consisted of fostering the child's awareness of the similarities between the task at hand and other tasks in situations familiar to the child (e.g., "This is like blowing bubbles in your tub"), pointing to the specific features of the performance process (e.g., "When you do this, pull the string, the bell moves and it rings"), or relating objects of joint activity to meaning systems in the child's culture. The two mediation scores were correlated (mother, $r=.66, p<.01, n=90$; caregiver, $r=.61, p<.01, n=90$; father, $r=.72, p<.01, n=42)$ and were summed into an Adult Mediation composite. Two trained coders who did not participate in the CIB coding coded the structured play, and reliability was conducted for 23 adult-child sessions: 9 with mothers, 9 with caregivers, and 5 with fathers. Reliability on all codes exceeded $87 \%$. The intraclass correlation averaged .91 (range $=.83-.95$ ).

Compliance situation: Child compliance and adult discipline. Microanalysis of child compliance and adult discipline was conducted on a computerized system (The Observer, Noldus Information Technology, Wageningen, The Netherlands). Two trained observers, who did not participate in the previous coding, coded while the tape was running at normal speed, shifting to slow motion when a shift in behavior occurred. Approximately four viewings per session were required to complete coding. Codes were defined in line with previous work (Feldman, Greenbaum, \& Yirmiya, 1999; Kochanska \& Aksan, 1995), and proportion variables were log-transformed prior to data analysis. Child Compliance included five mutually exclusive behaviors: self-regulated compliance (child's enthusiastic compliance to task, child displays positive affect and continues work without adult monitoring), externally motivated compliance (child complies but with no enthusiasm or positive affect, stops often, needs continuous reminders, leaves task when adult looks away), noncompliance (child does not comply but does not show anger, negativity, or struggle), defiance (child shows active disagreement, argues, screams, scatters the toys, etc.), and time-out (child takes time off from the task). Adult Discipline included three mutually exclusive behaviors: harsh control (adult uses physical force, insults, yelling, or manipulations), warm control (adult shows positive affect while providing consistent limits, uses tactics such as encouragement, redirection of attention, or praise, negotiates with the child, explains and suggests, and shows empathy in order to keep child on task), and no control (adult provides no structure, lets child do as he or she pleases with no attention to task, may pick up the toys for child). Reliability was computed on 12 child sessions with each adult. Reliability (kappa) averaged .80 for child compliance (range $=.79-.82$ ) and .79 for adult discipline (range $=.78-.80$ ).
Child emotion regulation. Emotion regulation was coded from the cognitive testing and considered the child's self-regulation in a challenging situation. Testing enabled the observation of the child's frustration tolerance, the change of behavior across time, and the cooperation with an unfamiliar adult. Five codes were coded on a scale of 1 to 5 and were averaged to create the Emotion Regulation composite $(\alpha=.71)$. These included on-task persistence, emotional lability (negative), cooperation with examiner, concentration, and frustration (negative). Reliability, measured on seven observations, averaged $86 \%$, and the intraclass correlation was .91 (range $=.81-.94)$.

Quality of caregiver relational style in the group. Microanalytic coding of the 90-min group sessions was conducted in 30-s epochs along eight categories, each containing a set of mutually exclusive codes. To provide an index of the caregiver's warm and accepting style, we computed the proportion of time in which the caregiver demonstrated positive affect, maintained visual contact with the children, and used a relaxed and warm tone of voice. Reliability testing was conducted for five sessions and averaged $88 \%(\kappa=.69)$. This score was used as a control variable in the analysis relating caregiver-child variables to child self-regulated compliance to the caregiver.

\section{Data Analytic Strategy: The Issue of Nonindependence}

A central data analytic problem in research on caregiver-child relationships is the nonindependence of observations. In this study, each caregiver interacted individually with 5 or 6 children. In order to address the problem of nonindependence in the correlation/regression analyses, we followed Deal's (1995) suggestions on using data from multiple family members. According to this view, one should extract the latent "group" factor from each variable and use the residualized score, which represents the "individual" variance while the shared variance is omitted. Each caregiverchild interaction variable (child self-regulated compliance to caregiver, caregiver warm control, caregiver sensitive regulation, child involvement with caregiver, and caregiver mediation) was regressed on 16 dummy "caregiver" variables, and the unstandardized residuals were then used in all of the following analyses. These residuals represent individual scores, independent of the caregiver's shared component, and were used in all correlations and regressions involving caregiver-child variables. In correlations and regressions that called for comparisons between caregiverchild variables and parent-child variables, parental variables were transformed into $z$ scores. For the analyses that examined mean-level stability, one case was randomly selected for each caregiver $(n=16)$ for each variable. These were then compared with a random selection of 16 motherchild cases and a random selection of 16 father-child cases.

\section{Results}

The results are reported in four sections. In the first section, we examine mean-level stability in child compliance and in adult sensitive regulation, mediation, warm control discipline, and childrearing philosophies among the three adults. In the second section, rank-order concordance among the three adults is assessed (Question 1 in the introduction). In the third section, partial correlations are used to examine the relations between the child's self-regulated compliance toward each adult and the child's cognitive level and emotion regulation, the adult's interactive behavior in the three contexts, and the adult's child-rearing philosophies, with potential confounding factors controlled (Question 2). In the final section, we present regression models predicting child self-regulated compliance to the caregiver from maternal variables and vice versa, and we test differences in the magnitude of the correlation coefficients (Question 3). 
Table 1

Descriptive Statistics for Mothers, Caregivers, and Fathers

\begin{tabular}{|c|c|c|c|c|c|c|c|c|c|}
\hline \multirow[b]{2}{*}{ Variable } & \multicolumn{2}{|c|}{$\begin{array}{l}\text { Mother } \\
(n=16)\end{array}$} & \multicolumn{2}{|c|}{$\begin{array}{l}\text { Caregiver } \\
(n=16)\end{array}$} & \multicolumn{2}{|c|}{$\begin{array}{l}\text { Father } \\
(n=16)\end{array}$} & \multirow{2}{*}{$\begin{array}{c}\text { Mother-father } \\
F(1,14)\end{array}$} & \multirow{2}{*}{$\begin{array}{c}\text { Mother-caregiver } \\
F(1,14)\end{array}$} & \multirow{2}{*}{$\begin{array}{c}\text { Father-caregiver } \\
\qquad F(1,14)\end{array}$} \\
\hline & $M$ & $S D$ & $M$ & $S D$ & $M$ & $S D$ & & & \\
\hline \multicolumn{10}{|l|}{ Adult and child interactive behavior } \\
\hline \multicolumn{10}{|l|}{ Compliance situation } \\
\hline Child self-regulated compliance ${ }^{a}$ & .20 & .23 & .25 & .25 & .28 & .30 & $4.26 *$ & 1.65 & 1.74 \\
\hline Adult warm control discipline ${ }^{\mathrm{a}}$ & .89 & .21 & .84 & .24 & .82 & .20 & 0.94 & 0.35 & 0.99 \\
\hline \multicolumn{10}{|l|}{ Free play } \\
\hline Adult sensitive regulation ${ }^{\mathrm{b}}$ & 3.25 & 0.43 & 3.34 & 0.36 & 3.12 & 0.49 & 0.22 & 0.43 & $8.28 * *$ \\
\hline Child social involvement ${ }^{\mathrm{b}}$ & 3.30 & 0.36 & 3.15 & 0.58 & 3.07 & 0.41 & $3.98 *$ & 1.20 & 2.96 \\
\hline \multicolumn{10}{|l|}{ Teaching session } \\
\hline Adult mediation $^{\mathrm{c}}$ & 8.68 & 7.27 & 12.75 & 8.85 & 7.21 & 8.84 & 0.62 & 2.32 & 2.53 \\
\hline \multicolumn{10}{|l|}{ Child-rearing philosophies } \\
\hline Perceived efficacy ${ }^{\mathrm{b}}$ & 4.03 & 0.62 & 4.22 & 0.45 & 4.04 & 0.93 & 0.01 & 0.57 & 0.02 \\
\hline Malleability of development ${ }^{\mathrm{b}}$ & 2.92 & 0.84 & 2.80 & 0.86 & 2.90 & 0.78 & 0.02 & 0.30 & 0.04 \\
\hline Relations with parent/caregiver ${ }^{\mathrm{b}}$ & 1.66 & 0.46 & 1.76 & 0.34 & 2.07 & 0.56 & $6.67 *$ & 0.29 & $5.22 *$ \\
\hline
\end{tabular}

${ }^{\mathrm{a}}$ Proportions of time. ${ }^{\mathrm{b}}$ Averages on a scale of $1-5 . \quad{ }^{\mathrm{c}}$ Frequencies.

$* p<.05 . \quad * * p<.01$.

\section{Mean-Level Stability Among Mothers, Caregivers, and Fathers}

Mean-level stability was examined with a series of univariate analyses of variance (ANOVAs) with repeated measures. A random case was selected for each caregiver $(n=16)$, and these were compared with 16 mother cases and 16 father cases. Child gender was included in all analyses as the between-subjects factor. Means for all variables and the $F$ values for mother-father, mothercaregiver, and father-caregiver comparisons are presented in Table 1.

Mother-father comparisons. As can be seen in Table 1, differences between mothers and fathers emerged for three variables. Children showed higher self-regulated compliance to their fathers and were more socially involved during interactions with their mothers. In addition, fathers placed more importance on the ongoing relationship between parents and caregivers.

A Parent $\times$ Child Gender interaction was found for the parents' warm control, $F(1,14)=3.85, p<.05$. Fathers used significantly more warm control strategies with daughters $(M=.94)$ than with sons $(M=.70), F(1,15)=3.86, p<.05$, whereas the difference between mothers' warm control toward daughters $(M=.90)$ and sons $(M=.87)$ was not significant. A Parent $\times$ Child Gender interaction was also found for the parent's sensitive regulation, $F(1,14)=3.78, p<.05$. Fathers were significantly more sensitive during interactions with daughters $(M=3.58, S D=0.27)$ than during interactions with sons $(M=2.84, S D=0.37), F(1$, $15)=3.86, p<.05$, whereas the difference between mothers' sensitive regulation toward daughters $(M=3.35, S D=0.50)$ and sons $(M=3.17, S D=0.27)$ was not significant.

Three main effects were found for child gender in mother-father comparisons. A main effect for child gender emerged for selfregulated compliance, $F(1,14)=3.86, p<.05$. Girls showed more self-regulated compliance toward both mothers $(M=.21)$ and fathers $(M=.35)$ than did boys (mothers, $M=.17$, fathers, $M=.25$ ). A main effect for gender was also found for the parents' sensitive regulation during free play, $F(1,14)=9.15, p<.01$ Both mothers and fathers showed higher sensitivity toward daughters than toward sons. Finally, girls were more socially involved during free play, $F(1,14)=9.46, p<.01$. Girls showed more involvement while interacting with both mothers $(M=3.46$, $S D=0.43)$ and fathers $(M=3.36 ; S D=0.27)$ than did boys (mothers, $M=3.17, S D=0.26$; fathers, $M=2.89, S D=0.38$ ).

Mother-caregiver comparisons. As can be seen in Table 1, no mean-level differences were found between mothers and caregivers on any of the interactive or child-rearing philosophies variables, which points to a global mean-level stability in mothers' and caregivers' styles and attitudes and in the child's interactive behavior with these two female agents.

Father-caregiver comparisons. Results presented in Table 1 indicate that caregivers displayed more sensitive regulation during play than did fathers, and fathers perceived the relations between parents and caregivers as more important than did caregivers. An interaction of social agent and child gender was found for the adult's sensitive regulation, $F(1,14)=3.92, p<.05$. Fathers showed significantly more sensitivity toward daughters, $F(1$, $15)=14.08, p<.01$, whereas caregivers' sensitivity toward boys $(M=3.32, S D=0.41)$ and girls $(M=3.37, S D=0.34)$ were comparable. $^{1}$

Finally, the dynamics of self-regulated compliance episodes were tested. The latencies to the first episode of self-regulated compliance to mothers $(5.34 \mathrm{~s})$ and to fathers $(5.47 \mathrm{~s})$ were shorter than that to caregivers $(7.24 \mathrm{~s}): t(1,15)=3.49, p<.05$ for caregivers versus mothers, and $t(1,15)=3.33, p<.05$ for caregivers versus fathers. On the other hand, episodes of internalized compliance to the caregiver lasted longer. The mean durations of compliance episodes were $34.5 \mathrm{~s}$ to mothers $(S D=19.3), 35.2 \mathrm{~s}$ to fathers $(S D=21.2)$, and $45.1 \mathrm{~s}$ to caregivers $(S D=22.3): t(1$,

\footnotetext{
${ }^{1}$ Similar ANOVAs conducted with the entire sample yielded the same results.
} 
$15)=3.35, p<.05$ for comparisons with mothers, and $t(1$, $15)=3.12, p<.05$ for comparisons with fathers. Thus, although no differences were found in the level of compliance to the three agents, it took children more time to reach internalized compliance to the caregiver, but once such compliance was achieved, children were able to persist longer in being compliant to the nonparental agent.

\section{Rank-Order Concordance Among Mothers, Caregivers, and Fathers}

Table 2 presents rank-order concordance among the three adults in interactive behavior and philosophies as well as in children's self-regulated compliance to the three agents. In general, the results point to medium-to-high concordance between mothers and fathers on nearly all measures (apart from the importance placed on the relations with the caregiver), which points to a general consistency in the co-parenting unit. Concordance was lower between caregivers and parents. Such concordance was found only for the discipline variables-self-regulated compliance and adult warm control. Correlations for the caregiver's child-rearing philosophies are not provided in Table 2 because of the nonindependence problem. Correlations between caregivers' child-rearing philosophies and both mothers' and fathers' philosophies were examined for a random set of 16 mothers and fathers, and none of the correlations was significant (range $=.00-.09$ ).

\section{Relations Between Self-Regulated Compliance and Child and Adult Factors}

To examine the relationship between the correlates of child compliance and children's self-regulated compliance to each social agent, we computed partial correlations between child compliance and child cognitive level, child emotion regulation, adult-child interactive behaviors in the three contexts, and adult child-rearing philosophies. The results are presented in Table 3. For the parentchild correlations, the analyses control for child gender and birth order, because the parent's experience in raising children may shape interaction styles and philosophies. For the caregiver-child correlations, analyses control for child gender and the four factors that are considered to index the quality of center care (e.g. Howes \& Olenick, 1986): caregiver education, caregiver experience, adult-to-child ratio, and the caregiver's warm style in the group.

As can be seen in Table 3, self-regulated compliance to each of the three adults was related to emotion regulation and adult warm control discipline, suggesting that child temperamental dispositions and an adult discipline style that combines dialogue and limits are consistently related to internalized compliance. Child self-regulated compliance to the parents was also related to the parent's sensitive regulation of the free play. Parents who had a higher sense of self-efficacy and who viewed child development as less predetermined and more open to social influences had children who showed higher self-regulated compliance. A more optimal maternal mediation of the teaching task was also related to child compliance to the mother. Self-regulated compliance to the caregiver had a closer association with child factors. Compliance to the caregiver was unrelated to the caregiver's behavior in nondisciplinary settings but correlated with child cognition, emotion regulation, and social involvement during free play. The relations between caregiver child-rearing philosophies and children's selfregulated compliance to the caregiver were examined in a random selection of 16 children, one for each caregiver. All correlations were nonsignificant (range $=.06-.13$ ).

Differences in the magnitudes of the correlation coefficients between mothers and caregivers were examined. Significant differences were found only for the coefficients relating mothers' and caregivers' sensitivity to child compliance to mother and caregiver, respectively, Fisher's $Z=1.97, p<.05$ (Cohen \& Cohen, 1983).

\section{Predicting Child Compliance to Caregiver From Mother- Child Interaction Variables}

In this final section, we examine whether maternal interactive behavior predicts children's self-regulated compliance to the care-

Table 2

Concordance in Adults' and Child's Behavior and Attitudes Among the Three Social Agents

\begin{tabular}{llcc}
\hline \multicolumn{1}{c}{ Variable } & $\begin{array}{c}\text { Mother-father } \\
(n=42)\end{array}$ & $\begin{array}{c}\text { Mother-caregiver } \\
(n=90)\end{array}$ & $\begin{array}{c}\text { Father-caregiver } \\
(n=42)\end{array}$ \\
\hline $\begin{array}{l}\text { Adult and child interactive behavior } \\
\text { Compliance situation }\end{array}$ & & & \\
$\quad$ Self-regulated compliance & $.42^{* *}$ & $.35^{* *}$ & $.33^{*}$ \\
$\quad$ Adult warm control & $.40^{* *}$ & $.22^{*}$ & .16 \\
Free play & $.46^{* *}$ & .17 & .16 \\
$\quad$ Adult sensitive regulation & $.40^{* *}$ & .20 & .10 \\
$\quad$ Child social involvement & $.73^{* *}$ & .18 & \\
Teaching session & $.55^{* *}$ & & \\
$\quad$ Adult mediation & $.65^{* *}$ & & \\
Child-rearing philosophies & .21 & & \\
$\quad$ Perceived efficacy & & & \\
Malleability of development & Relations with parent/caregiver & &
\end{tabular}

Note. Correlations for caregiver's child-rearing philosophies are omitted because of the nonindependence of observations.

$* p<.05$. ** $p<.01$. 
Table 3

Partial Correlations Relating Child Self-Regulated Compliance to the Three Social Agents With Adult and Child Variables

\begin{tabular}{|c|c|c|c|}
\hline \multirow[b]{2}{*}{ Variable } & \multicolumn{3}{|c|}{ Child self-regulated compliance } \\
\hline & $\begin{array}{l}\text { To mother } \\
(n=90)\end{array}$ & $\begin{array}{l}\text { To caregiver } \\
\quad(n=90)\end{array}$ & $\begin{array}{l}\text { To father } \\
(n=42)\end{array}$ \\
\hline Child developmental level (MDI) & .18 & $.34 * *$ & .17 \\
\hline Child emotion regulation & $.22 *$ & $.35^{* *}$ & $.30 *$ \\
\hline \multicolumn{4}{|l|}{ Adult and child interactive behavior } \\
\hline Adult warm control & $.40^{* *}$ & $.43 * *$ & $.42 * *$ \\
\hline \multicolumn{4}{|l|}{ Free play } \\
\hline Adult sensitive regulation & $.34 * *$ & .04 & $.33 *$ \\
\hline Child social involvement & .15 & $.26^{*}$ & .18 \\
\hline \multicolumn{4}{|l|}{ Teaching session } \\
\hline Adult mediation & $.24 *$ & .10 & .27 \\
\hline \multicolumn{4}{|l|}{ Child-rearing philosophies } \\
\hline Perceived efficacy & $.30 * *$ & & $.31 *$ \\
\hline Malleability of development & $.32 * *$ & & $.30 *$ \\
\hline Relations with parent/caregiver & .10 & & .18 \\
\hline
\end{tabular}

Note. Correlations including mothers' and fathers' variables control for child gender and birth order; correlations including caregiver variables control for child gender and caregiver's education, experience, adult-tochild ratio, and warm style in the group observation. $d f=86$ for mother variables, 83 for caregiver variables, and 38 for father variables. MDI = mental development index from the Bayley Scales of Infant Development. $* p<.05 . \quad * * p<.01$.

giver and vice versa. A regression approach was used to assess whether the entire set of maternal behaviors examined here, above and beyond children's cognition and emotion regulation, would predict child compliance to the nonmaternal figure. In the following regressions, child gender, cognitive level (MDI), and emotion regulation were entered first in order to partial out variance related to child-related effects. Maternal warm control was entered in the second step because this measure was collected in a setting similar to the one in which the criterion variable was collected and because it is theoretically the strongest predictor of child socialization. In the third, fourth, and fifth blocks, the mother's sensitive regulation during free play, the child's social involvement with the mother, and the mother's mediation strategies in the structured task, respectively, were entered. Using a parallel set of variables, the second regression examined the prediction from caregiverchild variables to the child's self-regulated compliance to the mother. Following the regression models, we examined differences in the magnitudes of the correlation coefficients according to Cohen and Cohen's (1983, p. 479) method for testing the differences in partial regression coefficients from the same sample. The zero-order correlations between the predictors for each adult, prior to the regressions, are presented in Table 4.

The results presented in Table 4 suggest that maternal sensitivity was related to children's cognition and emotion regulation, to maternal mediation, and to child social involvement. Maternal and paternal warm control tactics were related to child emotion regulation. The caregiver's sensitivity and warm control, on the other hand, were unrelated to children's cognition or emotion regulation. The two measures collected during free play-adult sensitive regulation and child social involvement-were significantly correlated in all three interactions.

The results of the regression models are reported in Table 5. As can be seen in Table 5, children's self-regulated compliance to the caregiver was uniquely related to children's developmental level and emotion regulation, to the mother's warm control, and to the mother's sensitive style, and the model as a whole was significant. The model predicting child compliance to the mother from the caregiver's behavior was not significant.

Tests of the differences in the beta coefficients indicated that the beta coefficient relating mother's warm control with self-regulated compliance to the caregiver was significantly higher than the coefficient relating caregiver's warm control with child compliance to the mother $(t=3.89, p<.01)$. Similarly, the coefficient relating child compliance to the caregiver with maternal sensitive regulation was higher than the coefficient relating compliance to the mother with the caregiver's sensitive approach $(t=2.95, p<$ $.05)$. Thus, whereas the child's internalized compliance to the caregiver was predicted by maternal interactive behavior, compliance to the mother was not found to be predicted by the behavior of the nonparental social agent. ${ }^{2}$

An exploratory analysis predicting child self-regulated compliance to the father from maternal variables, and vice versa, was conducted using similar regression models. Both models proved insignificant: $R^{2}=.08, F(7,33)=0.68, p>.10$ for child

\footnotetext{
${ }^{2}$ To determine whether maternal warm control added unique variance above and beyond that contributed by caregiver warm control, we conducted a similar regression predicting compliance to the caregiver from maternal variables with caregiver warm control entered at the fourth step prior to maternal warm control. The model was significant, $R^{2}$ total $=.35$, $F(8,80)=5.01, p<.001$. Caregiver warm control contributed unique variance, $\beta=.26, R^{2}=.04, F_{\text {change }}=3.61, p<.05$; maternal warm control added unique variance above and beyond caregiver warm control, $\beta=.31, R^{2}=.08, F_{\text {change }}=4.54, p<.05$; and maternal sensitive regulation made a significant contribution above and beyond maternal and caregiver warm control, $\beta=.28, R^{2}=.04, F_{\text {change }}=3.73, p<.05$.
} 
Table 4

Bivariate Correlations Between Predictor Variables for Mothers, Caregivers, and Fathers

\begin{tabular}{|c|c|c|c|c|c|c|}
\hline Variable & 1 & 2 & 3 & 4 & 5 & 6 \\
\hline \multicolumn{7}{|c|}{ Mothers $(n=90)$} \\
\hline 1. Child cognitive level & - & .04 & .16 & $.26^{*}$ & $.27 *$ & .02 \\
\hline 2. Child emotion regulation & & - & $.28 * *$ & $.20 *$ & .01 & .18 \\
\hline 3. Adult warm control & & & - & .11 & .02 & .04 \\
\hline 4. Adult sensitive regulation & & & & - & $.38 * *$ & $.25 *$ \\
\hline 5. Child social involvement & & & & & - & $.22 *$ \\
\hline 6. Adult mediation & & & & & & - \\
\hline
\end{tabular}

\begin{tabular}{|c|c|c|c|c|c|c|}
\hline \multicolumn{7}{|c|}{ Caregivers $(n=90)$} \\
\hline 1. Child cognitive level & - & .04 & .05 & .16 & .00 & .06 \\
\hline 2. Child emotion regulation & & - & .10 & .08 & .12 & .03 \\
\hline 3. Adult warm control & & & - & .10 & $.24 *$ & .14 \\
\hline 4. Adult sensitive regulation & & & & - & $.35^{* *}$ & $.22 *$ \\
\hline 5. Child social involvement & & & & & - & .15 \\
\hline 6. Adult mediation & & & & & & - \\
\hline
\end{tabular}

\begin{tabular}{|c|c|c|c|c|c|c|}
\hline \\
\hline \multicolumn{7}{|c|}{ Fathers $(n=42)$} \\
\hline 1. Child cognitive level & - & .04 & .21 & .00 & .15 & .13 \\
\hline 2. Child emotion regulation & & - & $.29 *$ & .10 & .20 & .07 \\
\hline 3. Adult warm control & & & - & .04 & .14 & .02 \\
\hline 4. Adult sensitive regulation & & & & - & $.55 * * *$ & $.52 * * *$ \\
\hline 5. Child social involvement & & & & & - & $.47 * *$ \\
\hline 6. Adult mediation & & & & & & - \\
\hline
\end{tabular}

compliance to the mother, and $R^{2}=.09, F(7,33)=0.85, p>.10$ for child compliance to the father. Although the difference in sample sizes does not allow a conclusive statement, it is possible that the prediction from one parent to the other may not be as strong as the prediction from maternal interactive behavior to the child's socialized behavior toward a nonkin female agent. ${ }^{3}$

\section{Discussion}

Most theories of social development presuppose that socialization begins at home and is generalized to children's relationships with adults outside the family setting. This assumption has not yet been subjected to systematic validation, nor can it be easily confirmed. The present study provides a first step by assessing consistencies in children's socialized behavior toward parents and nonparental social agents. The results show both mean-level and rank-order stability in toddler's self-regulated compliance to parents and caregivers. Internalized compliance to each social agent was related to the child's emotion regulation and the adult's warm control discipline, providing support for perspectives emphasizing the dual role of parenting and child temperament in socialization (Feldman, Greenbaum, \& Yirmiya, 1999; Kochanska, 1997) and extending these perspectives to nonparental adults. Maternal sensitivity and discipline predicted self-regulated compliance to the caregiver. This prediction was stronger than the prediction from caregiver sensitivity and discipline to the child's compliance to the mother and remained significant when we controlled for the caregiver's disciplinary tactics. Although the data cannot provide definitive proof of the hypothesis that socialization generalizes from the mother to other agents, the results are consistent with the theory and may further our understanding of socialization processes as children enter meaningful relationships outside the family.

Stability in toddlers' self-regulated compliance to the three social agents was observed in mean level and rank order, indicating a developmental phenomenon with high cross-setting consistency (Kagan, 1980; Rutter, 1984). Although children's compliance to fathers was higher than their compliance to mothers, self-regulated compliance to caregivers did not differ significantly from self-regulated compliance to either parent. Mean-level and rank-order stability was also observed for the adults' warm control discipline, which may suggest that more socialized children elicit a more optimal disciplinary approach from any adult in their environment. This high intersituation consistency in adult and child behavior was unique to the compliance setting. No rankorder concordance between parents and caregivers was found for any adult or child behavior in the free-play or teaching interactions. In line with the theory, it is possible that the domain of socialization is marked by a higher level of consistency between parents and other agents than are other domains of the parentchild relationship. Such consistency may be important in order to instill in children universal rules of proper social conduct.

Two factors emerged as repeated correlates of self-regulated compliance to the three adults: children's emotion regulation and

\footnotetext{
${ }^{3}$ An exploratory regression analysis predicting child compliance to the caregiver from maternal variables using a random subset of 42 mothers and caregivers showed results similar to those of the regression reported in Table 4 for the entire sample.
} 
Table 5

Regression Models Predicting Child Self-Regulated Compliance to Caregiver From Maternal Variables and Predicting Child Self-Regulated Compliance to Mother From Caregiver Variables

\begin{tabular}{|c|c|c|c|c|c|c|}
\hline \multirow[b]{2}{*}{ Variable } & \multicolumn{3}{|c|}{ Child compliance to caregiver } & \multicolumn{3}{|c|}{ Child compliance to mother } \\
\hline & $\beta$ & $R^{2}$ change & $F_{\text {change }}$ & $\beta$ & $R^{2}$ change & $F_{\text {change }}$ \\
\hline Child gender & .19 & .03 & 2.51 & .16 & .02 & 1.32 \\
\hline Bayley MDI & $.27^{*}$ & .06 & $3.94 *$ & .19 & .02 & .86 \\
\hline Emotion regulation & $.29 *$ & .07 & $4.13 *$ & $.20^{*}$ & .03 & 2.05 \\
\hline Maternal warm control & $.39 * *$ & .08 & $6.57 * *$ & .14 & .02 & .97 \\
\hline Sensitive regulation & $.31^{*}$ & .04 & $3.66^{*}$ & .03 & .00 & .13 \\
\hline Child involvement & .07 & .00 & .23 & .11 & .01 & .45 \\
\hline Adult mediation & .12 & .02 & .88 & .10 & .01 & .38 \\
\hline
\end{tabular}

Note. For child compliance to caregiver, $R^{2}$ total $=.31, F(8,80)=4.72, p<.01$; for child compliance to mother, $R^{2}$ total $=.11, F(7,81)=0.76, p>.10$. Bayley MDI $=$ Bayley Scales of Infant Development mental development index.

$* p<.05$. ** $p<.01$.

adults' warm control. The relations between children's emotion regulation and socialization to the mother have been reported previously (Feldman, Greenbaum, \& Yirmiya, 1999; Stifter et al., 1999), and child temperament has been shown to interact with parenting style to shape the development of conscience (Kochanska, 1995, 1997). The present findings demonstrate that children's emotion regulation is related to socialized behavior toward the father and the nonparental agent as well and may possibly contribute to children's compliance in any setting. Furthermore, the correlation between emotion regulation and the child's compliance to the caregiver remained significant even when we controlled for the quality of center care in terms of the caregiver's experience, education, adult-to-child ratio, and interactive style, factors that are important determinants in children's compliance (Howes \& Olenick, 1986), pointing to the strength of the association between emotion regulation and compliance. Similarly, the adult's warm control was related to child compliance in all interactions. The well-demonstrated relation of parental discipline that places clear boundaries, respects the child's autonomy, relies on dialogue, and minimizes power assertion with child socialization and internalization (Crockenberg, 1987; Kuczynski et al., 1987; Maccoby \& Martin, 1983) appears to be applicable in adult-child relationships outside the family as well. These findings suggest that adult behavior marked by respect, limits, and dialogue is conducive to child socialization in any relationship and lend further support to perspectives that stress the role of the adult's dialogical style in social and moral development (e.g., Emde, 1992; Kochanska, 1994).

In contrast to emotion regulation and adult warm control, other correlates of self-regulated compliance were relationship specific. Mothers' and fathers' sensitive regulation during free play and parental child-rearing philosophies that included a sense of efficacy and belief in the malleability of child development were related to internalized compliance to the parents. Compliance to the caregiver, on the other hand, was associated with child factors: cognitive skills, emotion regulation, and social involvement at play. Caregiver sensitivity, mediation, and child-rearing philosophies were unrelated to the child's compliance to the caregiver. ${ }^{4}$ Thus, whereas the entire range of parental behavior and attitudes may contribute to the development of socialized behavior, com- pliance to the nonparental agent appears to be unrelated to behaviors outside the immediate disciplinary encounter. It is possible that children do not have sufficient one-on-one interactions with the caregiver for her individual style and beliefs to have a lasting impact on them. It is also possible that more advanced, regulated, and socially involved children are more adept at demonstrating socialized behavior at child care or at eliciting optimal discipline from nonparental figures. Another explanation may relate to the fact that children's day-care experience is essentially a group experience, and factors related to the caregiver's style in the group, rather than to her one-on-one behavior, may be more meaningful to children's socialization in the child-care setting.

Maternal behavior in each interactive setting was associated with children's self-regulated compliance to the mother, including sensitivity during free play, mediation of the learning task, and warm control discipline. These maternal interactive patterns index the maternal dialogical style at different developmental stages spanning early infancy through the toddler years. Maternal sensitivity is established in the first weeks of life and constitutes a stable maternal attribute across infancy (Belsky, Rovine, \& Taylor, 1984; Feldman et al., 1997). Maternal elaboration of the child's symbolic output develops toward the end of the 1st year with the emergence of symbolic representation in word and gesture (Bretherton \& Bates, 1984), and active parental discipline begins in the 2 nd year of life along with the development of moral awareness (Kagan, 1984). In line with the theory, each stage of the maternal dialogical style may contribute to the development of child socialization. Dialogical parenting begins with maternal sensitive adaptation to the infant's signals and the provision of consistent presence, continues with the expansion of the child's symbolic world, and culminates in the parent's negotiation, respect, and clear guidelines. The two child-rearing philosophies associated with internalized compliance similarly index the two sides of the dialogical parental style. Efficacy concerns the parent's ability to provide

\footnotetext{
${ }^{4}$ Although the correlations between caregivers' philosophies and child compliance should be treated with caution because of the small $N$, the magnitude of the coefficients is low, suggesting little association between variables.
} 
boundaries and handle difficulties, whereas malleability relates to the parent's belief that development is open to social influences and can be modified by positive, supportive parenting.

The model predicting children's self-regulated compliance to the caregiver from child and maternal factors was significant, whereas the parallel prediction from caregiver interactive behavior to children's compliance to the mother was not. In particular, maternal sensitivity was uniquely predictive of children's compliance to the caregiver, above and beyond mothers' and caregivers' discipline. The centrality of maternal sensitivity to the social and emotional development of children has been repeatedly addressed in the attachment literature. The present results are consistent with both the attachment and socialization perspectives and emphasize the role of maternal sensitivity during nondisciplinary encounters in shaping children's socialized conduct toward parents as well as familiar adults outside the family setting. Thus, although the results cannot confirm the theoretical position that socialized behavior is generalized from parents to nonparental agents, the data are consistent with the theory, and the theory provides a plausible explanation for the findings. The preliminary findings that maternal and paternal interactive variables did not predict internalized compliance to the other parent may suggest that the mechanism of generalization is specific in agent and direction and operates primarily from the mother to nonmaternal female social agents. Other mechanisms, such as co-parenting, may be involved in the development of children's willing embrace of the maternal and paternal rules of conduct. However, these are preliminary hypotheses, and much further research is required to map the development of children's socialization as it is shaped by the growing number of caring adults children encounter throughout their childhood and adolescence.

Finally, gender-related differences were found in parents' and children's behaviors. In line with previous research (Lytton, 1979; Power et al., 1994), toddlers showed more self-regulated compliance to fathers, which suggests that children mobilize more regulatory efforts during encounters with their fathers or that fathers find ways to elicit more socialized behavior from young children. Also consistent with previous research (Kochanska et al., 2001) was the finding that girls showed more self-regulated compliance and were more socially involved during free play than were boys. Fathers also placed more value on the ongoing relationship between parents and caregivers than did either mothers or caregivers. In addition, more gender-related effects were found for fathers than for mothers or caregivers. Fathers showed higher levels of sensitive regulation and warm control discipline toward girls than toward boys. Differences related to parent and child gender in various measures of socialization have been described, including discipline, sex-typing behavior, parental speech, interactive patterns, and the relations between temperament and parenting, but the direction of the effects differs according to the domain studied, the child's age, and the research tool (Bezirganian \& Cohen, 1992; Eisenberg, Wolchik, Goldberg, \& Engel, 1992; Fagot \& Hagan, 1991; Leaper, 2000; Leaper, Anderson, \& Sanders, 1998). The present data are consistent with two meta-analyses demonstrating stronger gender-related differences for fathers across domains of socialization (Lytton \& Romney, 1991; Siegal, 1987). Future research examining gender-related effects in adult and child socialization should use a full Adult Gender $\times$ Kin matrix and include socialized behavior toward both male and female nonparental social agents.

\section{Methodological Issues in the Study of Caregiver-Child Relationships}

The methodological problem of nonindependence is inherent in the study of group contexts. Nonindependence issues are similarly inherent in research on family processes, for instance, in motherchild relationships with twins, triplets, or siblings. In this study, the issue of nonindependence was addressed in all analyses and dictated the data analytic approach. Only 16 cases were compared in the mean-level analyses, resulting in significantly lower degrees of freedom than in observed cases. In the correlation and regression analyses, only residualized variables were used. This limited the number of possible predictors and precluded the development of a full model from the data at hand. Such drawbacks, however, should not discourage research on the development of children's relationships with nonkin significant adults. Children's social worlds comprise many groups in which one adult forms meaningful relations with several children, as is the case in families, schools, clubs, sports activities, choirs, religious institutions, or army bases. Sophisticated methodology needs to be developed so that future research may move beyond the frequently studied mother-child dyad and explore the development of meaningful adult-child relationships within and outside the family.

\section{Cultural Processes, Limitations, and Future Research}

Some attributes of the Israeli society and child-care experience may be important to consider in the interpretation of the findings. Family composition in Israel is still traditional, and all children in the study came from two-parent middle-class families. Such selection criteria may have increased the homogeneity of the sample in comparison with samples in U.S. child-care research, possibly minimizing the effects of potential confounds. On the other hand, the level of Israeli center care is lower than that in many Western countries, and the difference primarily relates to the high adult-tochild ratio and the low formal training for caregivers (Sagi, KorenKarie, Gini, Ziv, \& Joels, 2002). These conditions may have had some effect on the caregivers' or children's interactive behavior. Another limitation of the study was that father-child data were available for only half of the sample. Although no differences were found between families, children, and caretakers for participants with and without father data on any of the variables studied here, it is possible that the fathers who participated comprise a subsample of highly involved or skilled fathers. Still, the major goal of the study was to compare children's self-regulated compliance to the mother with compliance to a nonmaternal familiar figure. Father data, albeit incomplete, were presented in order to provide preliminary comparisons among fathers, mothers, and caregivers, and much further research is required to understand the father's role in socialization.

The generalization of children's socialized behavior from home to the wider social world through childhood and beyond requires considerable further study. Future research may investigate the longitudinal relationships between mother-child relations prior to placement at child care and the child's compliance behavior to caregivers. Similarly, comparisons of child compliance to parents 
and nonparental adults in later childhood and adolescence merit further study. Inasmuch as current social theories tend to emphasize the foundation learned at home and practiced in the parentchild relationship and the relation of that foundation to the child's later moral sense and functioning within society, empirical research needs to follow theory in describing those links in detail.

\section{References}

Baumrind, D. (1967). Child care practices anteceding three patterns of preschool behavior. Genetic Psychology Monographs, 75, 43-88.

Baydar, N., \& Brooks-Gunn, J. (1991). Effects of maternal employment and child-care arrangements on preschoolers' cognitive and behavioral outcomes: Evidence from the children of the National Longitudinal Survey of Youth. Developmental Psychology, 27, 932-945.

Bayley, N. (1993). Bayley Scales of Infant Development: Administering and scoring manual. New York: Psychological Corporation.

Belsky, J. (1990). Developmental risks associated with infant day care: Attachment insecurity, noncompliance and aggression? In S. Chehraze (Ed.), Psychosocial issues in day care (pp. 37-68). Washington, DC: American Psychiatric Press.

Belsky, J., Rovine, M., \& Taylor, D. C. (1984). The Pennsylvania Infant and Family Development Project: II. The development of reciprocal interaction in the mother-infant dyad. Child Development, 48, 706-717.

Bezirganian, S., \& Cohen, P. (1992). Sex differences in the interaction between temperament and parenting. Journal of the American Academy of Child and Adolescent Psychiatry, 31, 790-801.

Bretherton, I., \& Bates, E. (1984). The development of representation from 10 to 28 months: Differential stability of language and symbolic play. In R. N. Emde \& R. J. Harmon (Eds.), Continuities and discontinuities in development (pp. 229-261). New York: Plenum Press.

Bridges, L. J., Connell, J. P., \& Belsky, J. (1988). Similarities and differences in infant-mother and infant-father interaction in the Strange Situation: A component process analysis. Developmental Psychology, 24, 92-100.

Cohen, J., \& Cohen, P. (1983). Applied multiple regression/correlation analysis for the behavioral sciences. Hillsdale, NJ: Erlbaum.

Crockenberg, S. (1987). Predictors and correlates of anger toward and punitive control of toddlers by adolescent mothers. Child Development, 58, 964-975.

Crockenberg, S., \& Litman, C. (1990). Autonomy as competence in 2-yearolds: Maternal correlates of child defiance, compliance, and selfassertion. Child Development, 26, 961-971.

Deal, J. E. (1995). Utilizing data from multiple family members: A withinfamily approach. Journal of Marriage and the Family, 57, 1109-1112.

Eisenberg, N., Wolchik, S. A., Goldberg, L., \& Engel, I. (1992). Parent values, reinforcement, and young children's prosocial behavior: A longitudinal study. Journal of Genetic Psychology, 153, 19-36.

Emde, R. N. (1992). Amae, intimacy, and the early moral self. Infant Mental Health Journal, 13, 34-42.

Erel, O., Oberman, Y., \& Yirmiya, N. (2000). Maternal versus nonmaternal care and seven domains of children's development. Psychological Bulletin, 126, 727-747.

Fagot, B. I., \& Hagan, R. (1991). Observations of parent reactions to sex-stereotyped behaviors: Age and sex effects. Child Development, 62, 617-628.

Feldman, R. (1998). Coding Interactive Behavior (CIB) manual. Unpublished manual, Bar-Ilan University, Ramat Gan, Israel.

Feldman, R. (2000). Parents' convergence on sharing and marital satisfaction, father involvement, and parent-child relationship at the transition to parenthood. Infant Mental Health Journal, 21, 176-191.

Feldman, R., Eidelman, A. I., Sirota, L., \& Weller, A. (2002). Comparison of skin-to-skin (Kangaroo) and traditional care: Parenting outcomes and preterm infant development. Pediatrics, 110, 16-26.
Feldman, R., Greenbaum, C. W., Mayes, L. C., \& Erlich, H. S. (1997). Change in mother-infant interactive behavior: Relations to change in the mother, the infant, and the social context. Infant Behavior and Development, 20, 153-165.

Feldman, R., Greenbaum, C. W., \& Yirmiya, N. (1999). Mother-infant affect synchrony as an antecedent to the emergence of self-control. Developmental Psychology, 35, 223-231.

Feldman, R., Masalha, S., \& Nadam, R. (2001). Cultural perspective on work and family: Dual-earner Israeli-Jewish and Arab families at the transition to parenthood. Journal of Family Psychology, 15, 492-509.

Feldman, R., Weller, A., Leckman, J. F., Kvint, J., \& Eidelman, A. I. (1999). The nature of the mother's tie to her infant: Maternal bonding under conditions of proximity, separation, and potential loss. Journal of Child Psychology and Psychiatry, 40, 929-940.

Fox, N. A., Kimmerly, N. L., \& Schafer, W. D. (1991). Attachment to mother/attachment to father. Child Development, 62, 210-225.

Goossens, F. A., \& van IJzendoorn, M. H. (1990). Quality of infants' attachment to professional caregivers in relation to infant-parent attachment and day-care characteristics. Child Development, 61, 832-837.

Harlap, S., Davis, A. M., Grower, M. B., \& Prywes, B. (1977). The Jerusalem Perinatal Study: The first decade (1964-1977). Israel Medical Journal, 13, 1073-1091.

Hastings, P. D., \& Rubin, K. H. (1999). Predicting mothers' beliefs about preschool-aged children's social behavior: Evidence for maternal attitudes moderating child effects. Child Development, 70, 722-741.

Hoffman, M. L. (1970). Conscience, personality, and socialization technique. Human Development, 13, 90-126.

Howes, C., \& Hamilton, C. E. (1992). Children's relationships with child care teachers: Stability and concordance with parental attachment. Child Development, 63, 867-878.

Howes, C., \& Matheson, C. (1992). Sequences in the development of competent play with peers: Social and social pretend play. Developmental Psychology, 27, 961-974.

Howes, C., \& Olenick, M. (1986). Family and child care influences on toddlers' compliance. Child Development, 77, 202-216.

Kagan, J. (1980). Perspectives on continuity. In O. G. Brim \& J. Kagan (Eds.), Constancy and change in human development (pp. 26-74). Cambridge, MA: Harvard University Press.

Kagan, J. (1984). The nature of the child. New York: Basic Books.

Kaler, S., \& Kopp, C. (1990). Compliance and comprehension in very young toddlers. Child Development, 61, 1997-2003.

Keren, M., Feldman, R., \& Tyano, S. (2001). Emotional disturbances in infancy: Diagnostic classification and interactive patterns of infants referred to a community-based infant mental health clinic. Journal of the American Academy of Child and Adolescent Psychiatry, 40, 27-35.

Klein, P. S. (1996). Early intervention: Cross-cultural experiences with a mediational approach. New York: Garland.

Klein, P. S., \& Alony, S. (1993). Immediate and sustained effects of maternal mediation behaviors in infancy. Journal of Early Intervention, 17, 177-193.

Klein, P. S., Weider, S., \& Greenspan, S. L. (1987). A theoretical overview and empirical study of mediated learning experience: Prediction of preschool performance from mother-infant interaction patterns. Infant Mental Health Journal, 8, 110-129.

Kochanska, G. (1991). Socialization and temperament in the development of guilt and conscience. Child Development, 62, 1379-1392.

Kochanska, G. (1994). Beyond cognition: Expanding the search for the early roots of internalization and conscience. Developmental Psychology, 30, 20-23.

Kochanska, G. (1995). Children's temperament, mothers' discipline, and security of attachment: Multiple pathways to emerging internalization. Child Development, 66, 597-615.

Kochanska, G. (1997). Multiple pathways to conscience for children with 
different temperaments: From toddlerhood to age 5. Developmental Psychology, 33, 228-240.

Kochanska, G., \& Aksan, N. (1995). Mother-child mutually positive affect, the quality of child compliance to requests and prohibitions, and maternal control as correlates of early internalization. Child Development, 66, 236-254.

Kochanska, G., Coy, K. C., \& Murray, K. T. (2001). The development of self-regulation in the first four years of life. Child Development, 72, 1091-1111.

Kochanska, G., \& Murray, K. T. (2000). Mother-child mutually responsive orientation and conscience development: From toddler to early school age. Child Development, 71, 417-431.

Kopp, C. B. (1982). Antecedents of self-regulation: A developmental perspective. Developmental Psychology, 18, 199-214.

Kuczynski, L. (1984). Socialization goals and mother-child interaction: Strategies for long-term and short-term compliance. Developmental Psychology, 20, 1061-1073.

Kuczynski, L., \& Kochanska, G. (1995). Function and content of maternal demands: Developmental significance of early demands for competent action. Child Development, 66, 616-628.

Kuczynski, L., Kochanska, G., Radke-Yarrow, M., \& Girinius-Brown, O. (1987). A developmental interpretation of young children's noncompliance. Developmental Psychology, 23, 799-806.

Lawrence, B. M. (1984). Conversation and cooperation: Child linguistic maturity, parental speech, and helping behavior of young children. Child Development, 55, 1926-1935.

Leaper, C. (2000). Gender, affiliation, assertion, and the interactive context of parent-child play. Developmental Psychology, 36, 381-393.

Leaper, C., Anderson, K. J., \& Sanders, P. (1998). Moderators of gender effects on parents' talk to their children: A meta-analysis. Developmental Psychology, 34, 3-27.

Lytton, H. (1979). Disciplinary encounters between young boys and their mothers and fathers: Is there a contingency system? Developmental Psychology, 15, 256-268.

Lytton, H. (1980). Parent-child interaction: The socialization process observed in twin and singleton families. New York: Plenum Press.

Lytton, H., \& Romney, D. M. (1991). Parents' differential socialization of boys and girls: A meta-analysis. Psychological Bulletin, 109, 267-296.

Maccoby, E. E. (1992). The role of parents in the socialization of children: An historical overview. Developmental Psychology, 28, 1006-1017.

Maccoby, E. E., \& Martin, J. A. (1983). Socialization in the context of the family: Parent-child interaction. In P. H. Mussen (Series Ed.) \& E. M. Hetherington (Vol. Ed.), Handbook of child psychology: Vol. 4. Socialization, personality, and social development (4th ed., pp. 1-101). New York: Wiley.
NICHD Early Child Care Research Network. (1998). Early child care and self-control, compliance and problem behavior at twenty-four and thirtysix months. Child Development, $691145-1170$.

Piaget, J. (1952). The origins of intelligence in children. New York: International Universities Press.

Power, T. G., McGrath, M. P., Hughes, S. O., \& Manire, S. H. (1994). Compliance and self-assertion: Young children's responses to mothers versus fathers. Developmental Psychology, 30, 980-989.

Rutter, M. (1984). Continuities and discontinuities in socioemotional development: Empirical and conceptual perspectives. In R. N. Emde \& R. J. Harmon (Eds.), Continuities and discontinuities in development (pp. 41-68). New York: Plenum Press.

Sagi, A., Koren-Karie, N., Gini, M., Ziv, Y., \& Joels, T. (2002). Shedding further light on the effects of various types and quality of early child care on infant-mother attachment relationship: The Haifa Study of Early Child Care. Child Development, 73, 1166-1186.

Sanders, M. R., Turner, K. M., Wall, C. R., Waugh, L. M., \& Tully, L. A. (1997). Mealtime behavior and parent-child interaction: A comparison of children with cystic fibrosis, children with feeding problems, and nonclinic controls. Journal of Pediatric Psychology, 22, 881-900.

Schaffer, H. R., \& Crook, C. K. (1980). Child compliance and maternal control techniques. Developmental Psychology, 16, 54-61.

Siegal, M. (1987). Are sons and daughters treated more differently by fathers than by mothers? Developmental Review, 7, 183-209.

Stayton, D. G., Hogan, R., \& Ainsworth, M. D. S. (1971). Infant obedience and maternal behavior: The origins of socialization reconsidered. Child Development, 42, 1057-1069.

Stifter, C. A., Spinard, T. L., \& Braungart-Rieker, J. M. (1999). Toward a developmental model of child compliance: The role of emotion regulation in infancy. Child Development, 70, 21-32.

van IJzendoorn, M. H. (1997). Attachment, emergent morality, and aggression: Toward a developmental socioemotional model of antisocial behavior. International Journal of Behavioral Development, 21, 703-727. van Ijzendoorn, M. H., Tavecchio, L. W. C., Stams, G. J., Verhoeven, M., \& Reiling, E. (1998). Attunement between parents and professional caregivers: A comparison of childrearing attitudes in different child-care settings. Journal of Marriage and the Family, 60, 771-781.

Vygotsky, L. S. (1978). Mind in society, Cambridge, MA: Harvard University Press.
Received November 13, 2001

Revision received January 14, 2003

Accepted January 17, 2003 